\title{
Assessment of stainless steel 348 fuel rod performance against literature available data using TRANSURANUS code
}

\author{
Claudia Giovedi ${ }^{1,}{ }^{*}$, Marco Cherubini $^{2}$, Alfredo $\mathrm{Abe}^{3}$, and Francesco D'Auria ${ }^{4}$ \\ ${ }^{1}$ LabRisco, University of São Paulo, Av. Prof. Mello Moraes 2231, São Paulo, SP, Brazil \\ 2 NINE, Nuclear and Industrial Engineering, Borgo Giannotti 19, 55100 Lucca, Italy \\ ${ }^{3}$ Nuclear and Energy Research Institute - IPEN/CNEN, Nuclear Engineering Center - CEN, Av. Prof. Lineu Prestes 2242, \\ São Paulo, SP, Brazil \\ ${ }^{4}$ UNIPI, University of Pisa, Largo L. Lazzarino 2, 56126 Pisa, Italy
}

Received: 13 October 2015 / Received in final form: 29 February 2016 / Accepted: 8 March 2016

\begin{abstract}
Early pressurized water reactors were originally designed to operate using stainless steel as cladding material, but during their lifetime this material was replaced by zirconium-based alloys. However, after the Fukushima Daiichi accident, the problems related to the zirconium-based alloys due to the hydrogen production and explosion under severe accident brought the importance to assess different materials. In this sense, initiatives as ATF (Accident Tolerant Fuel) program are considering different material as fuel cladding and, one candidate is iron-based alloy. In order to assess the fuel performance of fuel rods manufactured using iron-based alloy as cladding material, it was necessary to select a specific stainless steel (type 348) and modify properly conventional fuel performance codes developed in the last decades. Then, 348 stainless steel mechanical and physics properties were introduced in the TRANSURANUS code. The aim of this paper is to present the obtained results concerning the verification of the modified TRANSURANUS code version against data collected from the open literature, related to reactors which operated using stainless steel as cladding. Considering that some data were not available, some assumptions had to be made. Important differences related to the conventional fuel rods were taken into account. Obtained results regarding the cladding behavior are in agreement with available information. This constitutes an evidence of the modified TRANSURANUS code capabilities to perform fuel rod investigation of fuel rods manufactured using 348 stainless steel as cladding material.
\end{abstract}

\section{Introduction}

The available data shows that the steady state performance of steel cladding in the first PWR was considered excellent $[1,2]$. The material used in the early PWR was mainly AISI 304 ( $12 \%$ cold worked). Nonetheless, some reactors operated using annealed AISI 348, which presents a better corrosion resistance due to the addition of niobium and tantalum in its composition.

The substitution of stainless steel by zircaloy as cladding material was due to the lower absorption for thermal neutrons of the zirconium-based alloys which enables to operate with lower enrichment cost. Despite the stainless steel economics penalty, the main advantage of using this material as cladding comes from the reduction of the probability of the violent oxidation reaction that occurs with zirconium-based alloys at high temperatures, as it

\footnotetext{
* e-mail: claudia.giovedi@labrisco.usp.br
}

has occurred in the Fukushima Daiichi accident [3]. As a consequence of this, iron-based alloys once again can be considered as a good option to replace zirconium-based alloys as cladding material improving the safety under accident scenarios [4]. Considering the previous good experience of AISI 348 as cladding, this material could be again applied to replace zirconium-based alloys as PWR fuel cladding.

In order to evaluate the fuel performance of fuel rods using AISI 348 as cladding, it is necessary to modify the current fuel performance codes to insert correlations and properties of this material. In this sense, TRANSURANUS code appears as a good option due to its flexibility for different fuel rod designs and reactor types, time range of the problems to be treated and materials data bank, which includes AISI 316 (both 20\% cold worked and annealed correlations are programmed into the code) $[5,6]$.

The adapted version of the TRANSURANUS code to evaluate the AISI 348 performance under irradiation was assessed using Yankee Rowe available data from open 
Table 1. Austenitic stainless steel series 300 properties at room temperature [7-9].

\begin{tabular}{llll}
\hline Property & AISI 304 & AISI 316 & AISI 348 \\
\hline Density $\left(10^{3} \mathrm{~kg} / \mathrm{m}^{3}\right)$ & 8.0 & 8.0 & 7.9 \\
Rockwell-B hardness & 70 & 79 & 80 \\
Ultimate strength $(\mathrm{MPa})$ & 505 & 580 & 605 \\
Tensile strength at yield $(\mathrm{MPa})$ & 215 & 290 & 220 \\
Maximum elongation $(\%)$ & 70 & 50 & 40 \\
Elastic modulus $(\mathrm{GPa})$ & 200 & 193 & 200 \\
Poisson's ratio & 0.290 & 0.295 & 0.283 \\
Specific heat $\left(\mathrm{J} / \mathrm{g}^{\circ} \mathrm{C}\right)$ & 0.5 & 0.5 & 0.5 \\
Thermal conductivity $(\mathrm{W} / \mathrm{mK})$ & 16.2 & 16.3 & 16.4 \\
Thermal expansion coefficient $\left(10^{-6} / \mathrm{K}\right)$ & 17 & 17 & 17 \\
Melting point $\left({ }^{\circ} \mathrm{C}\right)$ & 1450 & 1427 & 1400 \\
\hline
\end{tabular}

literature. The reason why Yankee Rowe fuel rod was selected is because it was the unique PWR (for which information was available to the authors) in which AISI 348 was used as cladding material. The aim of this paper is to present the obtained results in the framework of this activity.

\subsection{TRANSURANUS code}

TRANSURANUS is a computer code for the thermal and mechanical analysis of fuel rods in nuclear reactors developed at the European Institute for Transuranium Elements (ITU). The code consists of a clearly defined mechanical-mathematical framework into which physical models can easily be incorporated [5].

In order to introduce the AISI 348 data in the TRANSURANUS code, a set of references has been searched and collected. A selection has been made in order to use reliable data, when necessary data are not available either values coming from similar stainless steel (AISI 347) or typical values (i.e. applicable for a variety of stainless steel) were used. A comparison of the main properties for non-irradiated annealed AISI 304, 316 and 348 is presented in Table 1. The data show that the properties for AISI 316 and AISI 348 are very close which enable to expect a similar performance for both materials under irradiation.

Based on the literature research, the following properties related to the annealed AISI 348 were introduced in the TRANSURANUS code to obtain the adapted version: elasticity constant, Poisson's ratio, strain due to swelling, thermal strain, thermal conductivity, creep strain (thermal and irradiation creep rate), yield stress, rupture strain, burst stress, specific heat, density and melting temperature.

It was assumed that correlations already programmed in TRANSURANUS for the AISI 316 are acceptable and validated enough being the TRANSUNARUS originally developed to deal with fast breeder reactor fuel and considering its validation program [6]. In addition, the new correlations related to the AISI 348 properties somewhat reflect the same structure of the equivalent formula already programmed for the AISI 316. These correlations similarities should (at least partially) ensure that code numerical stability issue is not to be expected.

The AISI 348 behavior predicted by the modified code version has been compared against AISI 316 behavior which is part of the original (hence validated) code version. In general, the two steels present, as expected, similar trends. AISI 316 has shown a bit more conservative results in respect to AISI 348.

\subsection{Description of Yankee Rowe NPP features}

The Yankee Rowe PWR has been owned and operated since startup in 1960 by the Yankee Atomic Electric Co. at Rowe, Massachusetts. The reactor and its initial core and stainless steel reloads were designed and built by Westinghouse. Yankee Rowe was the first fully commercial PWR of $250 \mathrm{MWe}$, which started up in 1960 and operated to 1992 [10]. Yankee Rowe produced 44 billion kilowatt-hours of electricity from 1961-1992 when it was permanently shutdown for economic reasons. The plant was successfully decommissioned between 1992-2007 with structures removed and the site restored to stringent federal and state remediation standards [11].

Starting from its 7 th cycle of operation, the reactor began to change to zircaloy cladding, the transition was completed with cycle 12 . The stainless steel clad reactor core consisted of 76 assemblies and 24 cruciform control rods. A typical stainless steel assembly was made up of 9 subassemblies each arranged in a $6 \times 6$ array, to make up an $18 \times 18$ fuel rod array. The subassemblies were tied together along their length to form a complete integral fuel assembly.

The clad material was both seamless and welded annealed AISI 348 and represents the only large scale fuel experience with this steel in a PWR. The chemical composition of the adopted AISI 348 is identical to the niobium stabilized AISI 347, with the exception of a $0.10 \%$ limit on tantalum to reduce the neutron absorption crosssection. The fuel rod was also unique in that 6 physically separated fuel stacks spaced by equally spaced stainless steel discs. Each segment contains about 25 pellets. The objective of such design was to minimize differential thermal expansion 
Table 2. Yankee Rowe general data and assumptions.

\begin{tabular}{lll}
\hline Parameter & Value & Remark \\
\hline Rod outside diameter $(\mathrm{cm})$ & 0.864 & {$[1,12]$} \\
Cladding thickness $(\mathrm{cm})$ & 0.053 & {$[1,12]$} \\
Gap size (diametral) $(\mathrm{cm})$ & 0.011 & {$[1,12]$} \\
Fuel rod pitch $(\mathrm{cm})$ & 1.153 & {$[1,12]$} \\
Fuel pellet diameter $(\mathrm{cm})$ & 0.747 & {$[1,12]$} \\
Fuel pellet density $(\%)$ & 93 & {$[1]$} \\
Fill gas internal rod pressure $(\mathrm{MPa})$ & 0.1 & The fuel rod is not pressurized [1] \\
Active fuel length $(\mathrm{cm})$ & 229.9 & {$[12]$} \\
Concentration of the gas components at the & $0.8 \mathrm{~N}_{2}$ & The fuel rod is not pressurized, then it was considered \\
beginning of the calculation & $0.2 \mathrm{O}_{2}$ & the air composition [1] \\
U235 enrichment degree $(\%)$ & 3.4 & {$[1,12]$} \\
Free volume in the upper plenum available & 4.359 & The plenum height assumption considered a conservative \\
for filling gas and fission gas $\left(\mathrm{cm}^{3}\right)$ & & value taking into account the fuel stack height \\
Coolant flow rate $\left(\mathrm{g} \mathrm{h}^{-1}\right)$ & $7.86 \times 10^{5}$ & {$[12]$} \\
Coolant temperature $\left({ }^{\circ} \mathrm{C}\right)$ & 252 & {$[1,12]$} \\
Coolant pressure $\left(\mathrm{MPa}^{-1}\right)$ & 14 & {$[1,12]$} \\
Average LHGR $\left(\mathrm{kW} \mathrm{m}^{-1}\right)$ & 11.4 & Average rod power given in the literature for the Yankee \\
& & Rowe fuel rods $[1,12]$ \\
Design LHGR $\left(\mathrm{kW} \mathrm{m}^{-1}\right)$ & 35.3 & Design rod power given in the literature for the Yankee \\
& & Rowe fuel rods $[1,12]$ \\
Maximum cladding temperature surface $\left({ }^{\circ} \mathrm{C}\right)$ & 343 & {$[1,12]$} \\
Average burnup $\left(\mathrm{MWd} \mathrm{tU}^{-1}\right)$ & 31000 & {$[1,12]$} \\
Neutron flux $\left(\mathrm{cm}^{-2} \mathrm{~s}^{-1}\right)$ & $6.3 \times 10^{13}$ & Average assumed value to achieve the final fluence level \\
& $6 \times 10^{21}$ & and burnup [1,12] \\
Final fluence level $\left(\mathrm{n} \mathrm{cm}^{-2}\right)$ & {$[1,12]$} \\
\hline
\end{tabular}

between fuel and clad. There were no reported stainless steel clad fuel failures. The average fuel rod heat generation rate was $114 \mathrm{~W} \mathrm{~cm}^{-1}$, the design rate was $353 \mathrm{~W} \mathrm{~cm}^{-1}$ (with a peak as high as $410 \mathrm{~W} \mathrm{~cm}^{-1}$ ). The maximum cladding surface temperature was $343{ }^{\circ} \mathrm{C}$. A total of 16 assemblies were examined, all the assemblies were in excellent conditions with a minor amount of crud deposited [1].

\section{Methodology}

\subsection{Yankee Rowe general data and assumptions}

In order to prepare the input deck to perform the simulation considering the Yankee Rowe reactor design and operational parameters, it was collected in the literature all the available data, which are presented in Table 2 as well as the necessary assumptions.

\subsection{TRANSURANUS model and assumptions}

The simulations were carried out adopting the recommended TRANSURANUS models for PWR. The geometric characteristics, thermal-hydraulic parameters and power profile obtained from the literature for the Yankee Rowe fuel rod were implemented in the TRANSURANUS input deck according to the data presented in Table 2.

Considering that in TRANSURANUS code the analysis is performed slice per slice, it was necessary to assume a discretization for the Yankee Rowe fuel rod, which is presented in Figure 1. In order to prepare this model, it was considered the following information: the fuel rod had six physically separated fuel stacks with a perforated stainless steel disk between them localized at equally spaced axial locations, each segment contains about $25 \mathrm{UO}_{2}$ pellets, the active fuel length is $229.9 \mathrm{~cm}$ and the height of the fuel pellet is $1.46 \mathrm{~cm} \mathrm{[1,12].}$

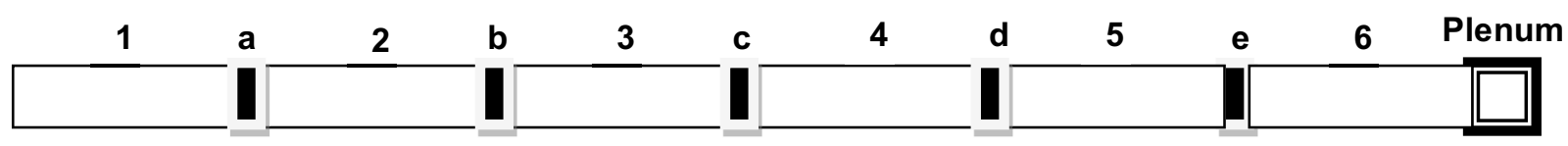

\section{$1,2,3,4,5,6: 36.5 \mathrm{~cm}$ ( 25 fuel pellets) divided in 4 segments each one of $91 \mathrm{~mm}$ (apart the first two meshes of $85 \mathrm{~mm}$ ); a, b, c, d, e: $40 \mathrm{~mm}$ (stainless steel disk); Plenum: $140 \mathrm{~mm}$}

Fig. 1. Yankee Rowe fuel rod assumed discretization based on the literature data [1]. 
a)

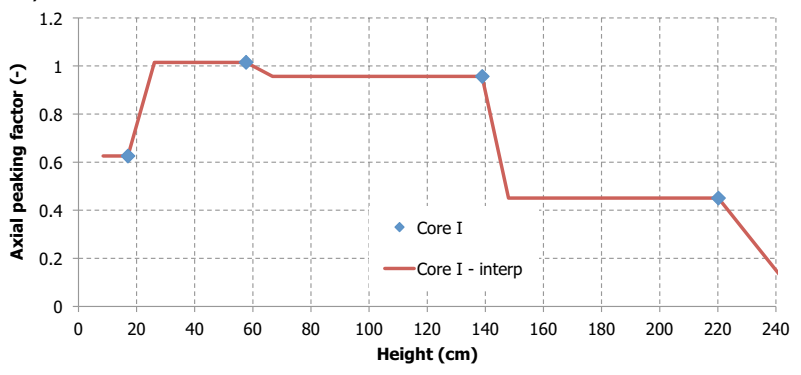

b)

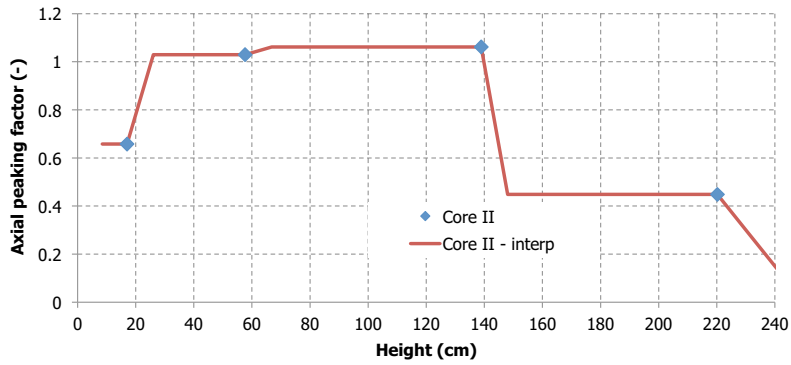

c)

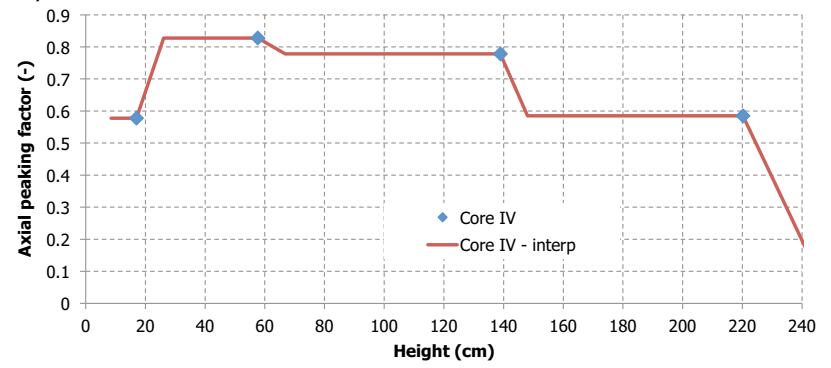

Fig. 2. E6-C-f6 fuel rod axial peaking factor for Core I (a), Core II (b) and Core IV (c), available data (blue dots [12]) and related interpolation (red curve).

The plenum length is not presented in the literature. Then, for calculation was assumed a value of $14 \mathrm{~cm}$, which represents a conservative value for a PWR fuel rod with an active length of $229.9 \mathrm{~cm}$.

The cladding and pellet roughness are also not presented in the literature for the Yankee Rowe fuel rod, and then it was assumed typical values for PWR. The same was considered for grain diameter, open porosity and plenum spring characteristics.

The simulation to assess the behavior of the Yankee Rowe fuel rod was carried out considering the information related with the rod E6-C-f6 as described in reference [12]. The selected rod target of the present simulation was irradiated into three core cycles identified as Core I, Core II and Core IV. Boundary conditions and axial power profile have been derived from reference [12]. Noticeably the axial power profile has been derived considering the average core power reported in Table 2. Data related with E6-C-f6 fuel rod are available in four axial positions, which have been interpreted as average values along the related length. Thus, constant piecewise trend has been adopted into TRANSURANUS simulation (Fig. 2). The calculated peaking factors have been imposed both to the linear power and to the neutron flux. The resulting profile is bottom skewed for the cycles Core I and II where the power was controlled by control rods, rather in Core IV boron was introduced as chemical shim resulting in a flatter axial profile [13].

The irradiation period is consistent with the information available in reference [12], adding $24 \mathrm{~h}$ for the power rise, $12 \mathrm{~h}$ for the power decrease, in addition $48 \mathrm{~h}$ has been set as shutdown period between two core cycles.
Finally, an average neutron flux equal to $6.3 \times 10^{13} \mathrm{n} \mathrm{cm}^{-2} \mathrm{~s}^{-1}$ has been set in order to achieve a fluence level close to the value available in the literature, i.e. $6.0 \times 10^{21} \mathrm{n} \mathrm{cm}^{-2}$. Regarding the fuel-cladding contact model, the perfect slip model has been adopted.

\section{Results and discussion}

The results obtained from the Yankee Rowe fuel model are shown hereafter. Table 3, Table 4 and Table 5 list, respectively, the outcomes of the simulation at the end of the Core I, Core II and Core IV cycle, compared with available information taken from reference [12]. It should be noted that no tuning has been done for carrying out the simulation.

The parameters attaining to the Core I cycle are reasonably reproduced by the TRANSURANUS code (Tab. 3), noticeably the burnup matches fairly good in all four locations.

Regarding the fuel temperature calculated by the code, centerline and surface values are provided since for the reference data no specification about the radial position is provided. It can be seen that reference fuel temperature is within the code prediction for all the four axial positions.

The same considerations apply for the clad temperature (apart for the top position which is slightly underpredicted due to the underestimation of the coolant temperature) in relation with both reference data radial position and calculated values.

Additional calculated data are provided in Table 3 regarding fission gas release which remains very low; fuel and clad axial elongation, both are lower than 0.5\%; maximum fluence value and plenum pressure which is double of its starting value. 


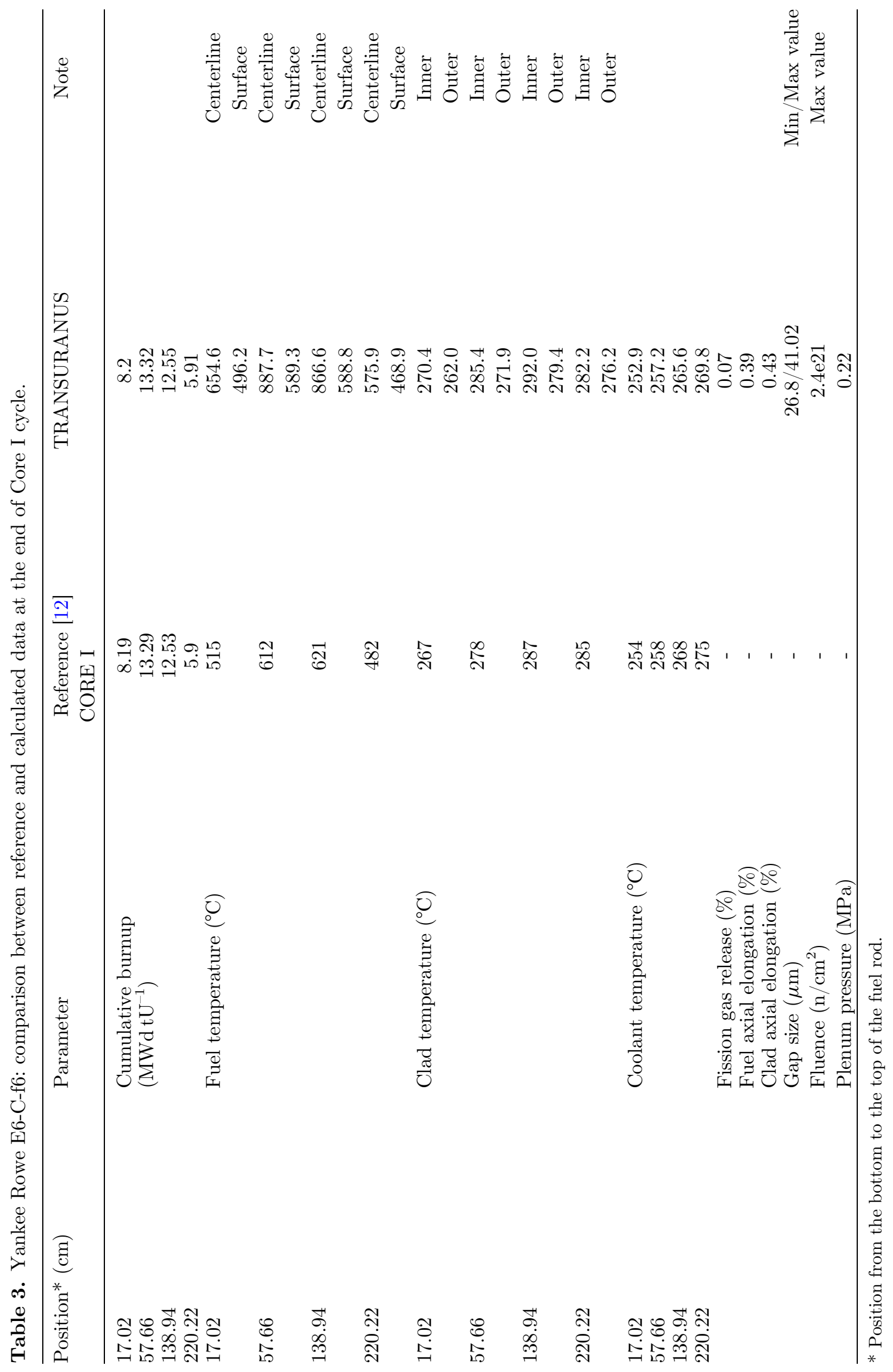




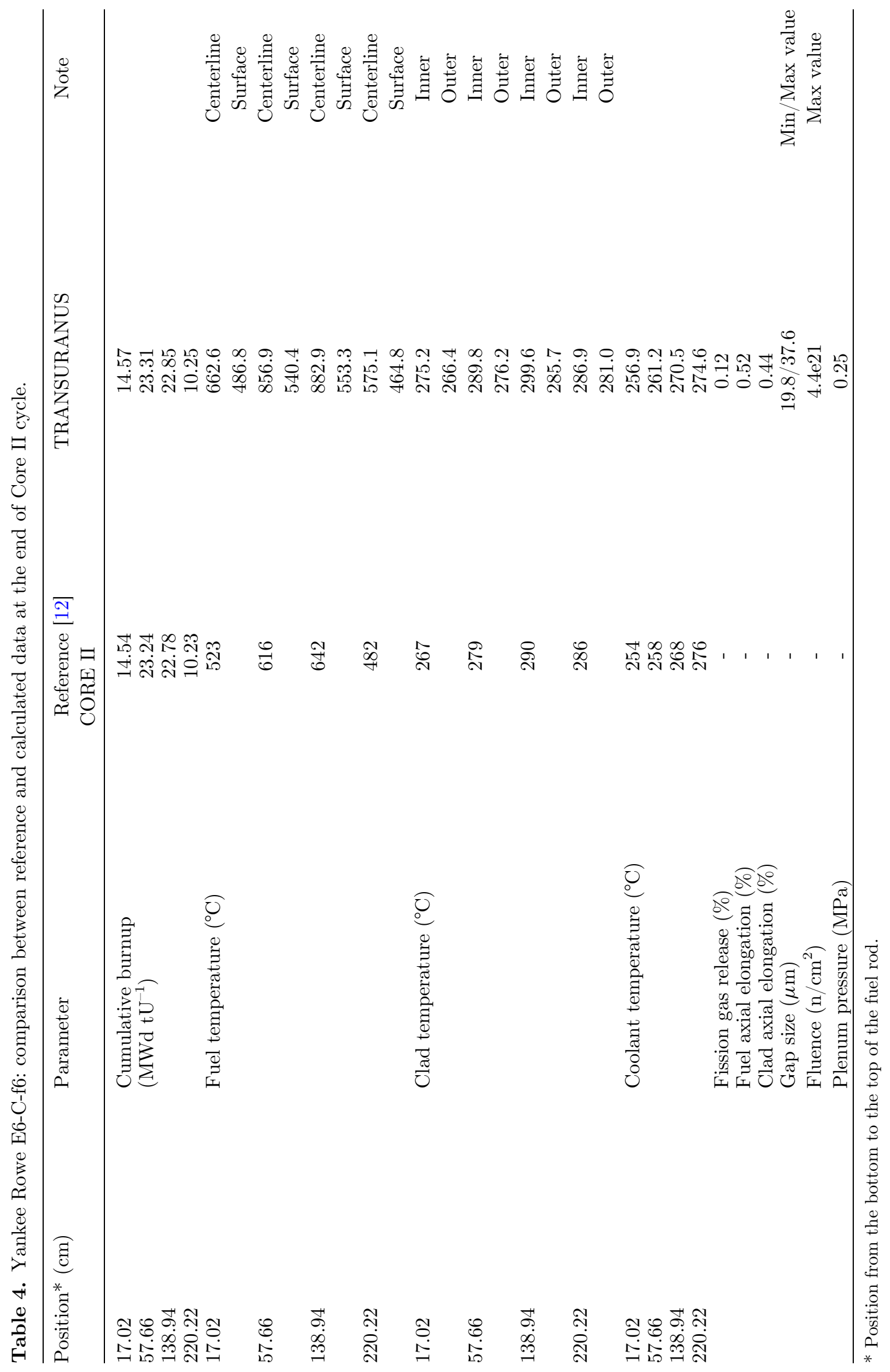


Table 5. Yankee Rowe E6-C-f6: comparison between reference and calculated data at the end of Core IV cycle.

\begin{tabular}{|c|c|c|c|c|}
\hline Position* (cm) & Parameter & $\begin{array}{l}\text { Reference [12] } \\
\text { CORE IV }\end{array}$ & TRANSURANUS & Note \\
\hline 17.02 & \multirow{4}{*}{$\begin{array}{l}\text { Cumulative burnup } \\
\left(\mathrm{MWd} \mathrm{tU}^{-1}\right)\end{array}$} & 20.19 & 20.25 & \\
\hline 57.66 & & 31.33 & 31.45 & \\
\hline 138.94 & & 30.39 & 30.50 & \\
\hline 220.22 & & 15.95 & 15.99 & \\
\hline \multirow[t]{2}{*}{17.02} & \multirow[t]{8}{*}{ Fuel temperature $\left({ }^{\circ} \mathrm{C}\right)$} & 504 & 606.4 & Centerline \\
\hline & & & 449.2 & Surface \\
\hline \multirow[t]{2}{*}{57.66} & & 574 & 716.7 & Centerline \\
\hline & & & 462.8 & Surface \\
\hline \multirow[t]{2}{*}{138.94} & & 575 & 702.3 & Centerline \\
\hline & & & 466.0 & Surface \\
\hline \multirow[t]{2}{*}{220.22} & & 525 & 641.6 & Centerline \\
\hline & & & 484.5 & Surface \\
\hline \multirow[t]{2}{*}{17.02} & Clad temperature $\left({ }^{\circ} \mathrm{C}\right)$ & 270 & 272.4 & Inner \\
\hline & & & 264.7 & Outer \\
\hline \multirow[t]{2}{*}{57.66} & & 277 & 282.4 & Inner \\
\hline & & & 271.4 & Outer \\
\hline \multirow[t]{2}{*}{138.94} & & 284 & 287.3 & Inner \\
\hline & & & 277.0 & Outer \\
\hline \multirow[t]{2}{*}{220.22} & & 288 & 286.8 & Inner \\
\hline & & & 279.0 & Outer \\
\hline 17.02 & Coolant temperature $\left({ }^{\circ} \mathrm{C}\right)$ & 258 & 256.7 & \\
\hline 57.66 & & 261 & 260.0 & \\
\hline 138.94 & & 267 & 266.3 & \\
\hline \multirow[t]{7}{*}{220.22} & & 276 & 271.1 & \\
\hline & Fission gas release (\%) & - & 0.17 & \\
\hline & Fuel axial elongation (\%) & - & 0.58 & \\
\hline & Clad axial elongation (\%) & - & 0.43 & \\
\hline & Gap size $(\mu \mathrm{m})$ & - & $16.4 / 32.6$ & Min/Max value \\
\hline & Fluence $\left(\mathrm{n} / \mathrm{cm}^{2}\right)$ & - & $5.9 \mathrm{e} 21$ & Max value \\
\hline & Plenum pressure $(\mathrm{MPa})$ & - & 0.26 & \\
\hline
\end{tabular}

* Position from the bottom to the top of the fuel rod.

Table 4 compares reference and calculated data related with the Core II cycle. Also for this irradiation step the code gives reasonable results, showing the same (as in Core I) good compliance regarding the burnup data.

Calculated values of fuel and clad temperature include the corresponding reference data. Notwithstanding the accumulation of the burnup, the fission gas release is still low $(0.12 \%)$; fuel and clad axial elongation do not change so much from the previous cycle (both slightly increased); the gap is reducing but still open; the plenum pressure is slightly increased from the previous cycle.

Table 5 reports the comparison discussed above but at the end of the Core IV cycle. Also at this stage of the simulation, the code shows the same capabilities in relation with the burnup, fuel and clad temperature. Coolant temperature is also reasonably predicted as well.
At the end of the whole simulation, the fission gas release is below $0.2 \%$; fuel and clad elongation are well below 1\%; the gap kept open with a minimum value of about $16 \mu \mathrm{m}$ (about $1 / 4$ of its initial value) and the plenum pressure is less than the triple of its initial value.

In relation with the fuel and clad relative elongation it can be seen that the code is able to reproduce one of the objective of the particular Yankee Rowe rod design, namely to minimize the differential thermal expansion between fuel and clad.

In general, the TRANSURANUS code performed reasonably well even facing with a rod design which is quite far from the typical (current) PWR technology (e.g. clad material, filling gas type, lack of gap pressurization, presence of different segments within the fuel rod). Any predicted parameters for the simulated fuel rod are of no concern regarding their corresponding design data. 


\section{Conclusion}

The assessment of the modified TRANSURANUS code benefits of the availability in the open literature of data related with Yankee Rowe NPP, which was one of the few plants in which AISI 348 has been used as cladding material. A specific Yankee Rowe fuel model has been set up, fully considering the available information and doing some assumptions for covering some lacks (e.g. fuel rod upper plenum height). When such assumptions had to be made, conservative values have been adopted (considering Yankee Rowe and typical PWR rod design).

The carried out calculations show reasonably agreement with available data confirming the modified code capabilities. This constitutes an indication of the modified TRANSURANUS code capabilities to perform fuel rod investigation of fuel rod manufactured with AISI 348 cladding material.

The authors are grateful to the technical support of USP, IPEN$\mathrm{CNEN} / \mathrm{SP}$ and to the financial support of IAEA to attend the TopFuel 2015 meeting.

\section{References}

1. S.M. Stoller Corporation, An evaluation of stainless steel cladding for use in current design LWRs, NP-2642, EPRI, 1982

2. V. Pasupathi, Investigations of stainless steel clad fuel rod failures and fuel performance in the Connecticut Yankee Reactor, EPRI 2119, 1981
3. N. Akiyama et al., The Fukushima nuclear accident and crisis management-Lessons for Japan-US Alliance Cooperation (Sasakawa Peace Foundation, Tokyo, 2012)

4. K.A. Terrani, S.J. Zinkle, L.L. Snead, Advanced oxidationresistant iron-based alloys for LWR fuel cladding, J. Nucl. Mater. 448, 420 (2014)

5. K. Lassman, TRANSURANUS: a fuel rod analysis code ready for use, J. Nucl. Mater. 188, 295 (1992)

6. European Commission, Joint Research Centre, Institute for Transuranium Elements, TRANSURANUS HANDBOOK, Document Number Version 1 Modification 1 Year 2012 ('V1M1J12'), 2012

7. D.L. Hagrman, G.A. Reymann, MATPRO - version 11. A handbook of materials properties for use in the analysis of light water reactor fuel rod behavior (Idaho National Engineering Lab, Idaho Falls, USA, 1979)

8. D. Peckner, I.M. Bernstein, Handbook of stainless steels (MacGraw Hill, New York, 1977)

9. Sandvik "Sandvik 8R40 data sheet" updated 20131128, http://www.smt.sandvik.com/en/

10. http://www.world-nuclear.org, accessed October 22, 2014

11. http://www.yankeerowe.com/pdf/Yankee\%20Rowe.pdf, accessed October 22, 2014

12. Burnup Credit - Contribution to the Analysis of the Yankee Rowe Radiochemical Assays, 1022910, EPRI, 2011

13. R.J. Nodvik et al., Supplementary Report on Evaluation of Mass Spectrometric and Radiochemical Analyses of Yankee Core I Spent Fuel, Including Isotopes of Elements Thorium Through Curium, TID 4500 (Westinghouse Electric Corporation, Pittsburgh, Pennsylvania, 1969)

Cite this article as: Claudia Giovedi, Marco Cherubini, Alfredo Abe, Francesco D'Auria, Assessment of stainless steel 348 fuel rod performance against literature available data using TRANSURANUS code, EPJ Nuclear Sci. Technol. 2, 27 (2016) 